\title{
0 Planejamento da velhice na perspectiva de estudantes universitários
}

\author{
Oldness planning from university students perspective
}

\section{Patrícia Garcia e Cássia Ferrazza Alves ${ }^{2}$}

Resumo: $O$ presente artigo tem como objetivo compreender o planejamento da velhice nas famílias contemporâneas a partir da percepção de estudantes universitários, haja vista o crescimento da população idosa, tornando-se uma população majoritária no Brasil nos próximos anos. Foi realizado um estudo qualitativo, através de dois grupos focais, com 10 estudantes universitários de uma Instituição de Ensino Superior (IES) privada do interior do Rio Grande do Sul. Os dados foram analisados através de análise temática. A partir da análise, foi possível identificar que a temática do envelhecimento e a velhice vem rodeada de tabus e medos, perpetuados pela sociedade. De forma quase simbiótica à velhice, a finitude tem sido associada, o que induz o sentimento de negação tanto dos avós e pais, quanto dos próprios estudantes universitários ao perceberem o envelhecimento. Desse modo, verificou-se dificuldade de falar abertamente e planejar a velhice na família dos jovens investigados.

Palavras-chave: Planejamento da velhice; Idosos; Estudantes universitários.

\section{Introdução}

0 processo de envelhecimento é algo que se fazia presente nas mais remotas histórias da humanidade, contendo, desde então, conflitos e inquietudes a respeito. Nesse sentido, "0 envelhecimento (processo), a velhice (fase da vida) e o velho ou idoso (resultado final) constituem um conjunto
Abstract: The present article has the goal to understand the planning of oldness in contemporary families by the perception of university students, given the grown of old population, becoming a majoritary population in Brasil over the next years. A qualitative study has been performed, through two focus groups, with 10 (tem) university students of a private Higher Education Institute from the interior of Rio Grande do Sul. The data were analised by thematic analysis. By the analysis, it was identified that the theme of aging e oldness comes surrounded by taboos and fears, perpetuated by the society. In an almost symbiotic way, oldness has been associated to finitude, which induces the feeling of denial by both grandparents and parents, as well as from the university students themselves, when perceiving the oldness. This way, it has been verified a difficulty of speaking openly and planning the old age in the family of the students.

Keywords: Oldness planning; Seniors; University students.

\footnotetext{
1 Psicóloga pela FSG Centro Universitário; Rua Independência, 645/408, Farroupilha; e-mail: ppatriciagarcia@hotmail.com .

2 Psicóloga, Doutora em Psicologia/UFRGS, Docente da FSG Centro Universitário; Rua Alfredo Chaves, 1208/1411; Caxias do Sul, e-mail: cassiaferrazza@gmail.com .
} 
das condições de vida do ser humano. Por conseguinte, com passos largos, a população mundial idosa e brasileira vem crescendo, sendo que há estimativas para os próximos anos de se tornar uma população majoritária no Brasil (Miranda, Mendes \& Silva, 2016).

Em 1970, com a revolução industrial, o Brasil teve seu perfil demográfico transformado radicalmente. Devido à entrada da mulher no mercado de trabaIho, na época fomentada pelo baixo custo dos salários, as mulheres deixaram seu papel exclusivo de cuidadoras do lar e de seus familiares, consideradas como de cuidadoras "oficiais", para ajudar no sustento da família e serem provedoras da casa (Camarano \& Kanso, 2017; Miranda, Mendes \& Silva, 2016). Mudança essa que afeta diretamente as famílias na sua capacidade de ofertarem o cuidado para o idoso (Camarano \& Kanso, 2017).

Assim, ao longo dos anos, modificações importantes ocorreram corroborando para essa mudança demográfica expressiva. As taxas de fertilidade caíram e, em contrapartida, a expectativa de vida aumentou, alterando não somente a densidade demográfica, mas também as novas configurações familiares, novos papéis e, com isso, novos desafios. Logo com a chegada da velhice, há papéis que mudam, em especial, com a aposentadoria, a saída dos filhos de casa, a presença de netos, entre outros fatores que modificam a dinâmica familiar e as relações hierárquicas. A partir dessas mudanças, por vezes, há uma necessidade de um novo arranjo e redefinições de papéis (Reis \& Monteiro, 2016).

Desse modo, torna-se oportuno abordar sobre a temática da família e do envelhecimento, podendo levantar como problema de pesquisa: Como tem sido o planejamento da velhice nas famílias contemporâneas? A fim de poder compreender essas modificações ao decorrer do tempo, a produção científica foi ganhando força e aumentando de forma gradativa, suas teorias e paradigmas. Embora seja necessário seu estudo, ainda é um tema recente na literatura brasileira.

Ao abordar o tema do planejamento da velhice, verificam-se questões relacionadas às condições financeiras e de saúde como um dos principais limitadores da autonomia na velhice (Faller, Teston \& Marcon, 2015; Brito, Belloni, Castro, Camargo \& Giacomozzi, 2018). Além disso, mudanças nas questões previdenciárias também influenciam neste aspecto (Brasil, 2015). A dependência da família tem sido considerada algo indesejável para muitos idosos e, diante de alguma doença, é necessário contar com a ajuda de um cuidador, o qual geralmente é familiar (Brito et al., 2018). Muitas vezes, essa dependência parece ser aprendida na medida em que a própria família representa o idoso como alguém que precisa de cuidados, amparo e atenção (Araújo, Castro \& Santos, 2018). Desse modo, verifica-se que não é somente o indivíduo que precisa refletir sobre a velhice, mas todo o contexto familiar, que possui representações sociais sobre a velhice, influenciando na qualidade do envelhecer (Araújo, Castro \& Santos, 2018; Faller, Teston \& Marcon., 2015).

Para compreender este aspecto, Moscovici (1961 citado por Morera, Padilha, Silva \& Sapag, 2015) na sua tese de doutorado La psychanalyse, sonimage et sonpublic, criou a Teoria das Representações Sociais (TRS), 0 qual compreendeu os fenômenos coletivos por meio das normas e regras que conduzem o pensamento social e fazem com que as representações se movimentem no meio de diferentes conceitos e percepções (Morera et al., 2015). Assim, a TRS está intimamente relacionada com as trocas simbólicas desenvolvidas nos ambientes sociais e nas relações interpessoais, influenciando na construção do conhecimento que é partilhado.
Nessa perspectiva, a população idosa vivencia com tensão essa nova fase, tendo dificuldades de estabelecer o seu novo papel e seu novo lugar na sociedade. Ao investigar as representações sociais da velhice, no geral, verificam-se aspectos ligados à inatividade e inutilidade dos idosos (Brito et al., 2018; Faller, Teston \& Marcon, 2015), ao declínio físico e a aparição de doenças (Araújo, Castro \& Santos, 2018; Brito etal., 2018; Mendes et al., 2018), a comparação do idoso à criança (Brito et al., 2018; Mendes et al., 2018), 0 desejo por autonomia e, por isso, a manutenção de atividades (Araújo, Castro \& Santos, 2018; Brito et al., 2018).

Logo, ao abordar a temática do planejamento da velhice, é necessário levar em conta que a maior parte dos idosos talvez não possua condições econômicas adequadas para vivenciar esta fase da vida, considerando que a condição econômica é um dos pilares do envelhecimento ativo e um importante aspecto para muitos idosos ao investigar a percepção de envelhecimento (Brito et al., 2018; Faller, Teston \& Marcon, 2015). Por isso, torna-se imprescindível a existência de políticas públicas voltadas para a população idosa (Brito et al., 2018), bem como a capacitação de profissionais para trabalhar com esta população (Faller, Teston \& Marcon, 2015). Cachioni e Aguilar (2008) afirmam que o papel da universidade perante a sociedade não é só de formar o estudante em seu curso, mas dar subsídios para que esses sujeitos possam ter o conhecimento científico e empático, modificando a imagem do idoso no contexto social. Contudo, ao investigar as representações sociais dos universitários sobre a velhice, ainda se identificam concepções calcadas em um modelo biomédico, relacionando à velhice ao declínio físico e à aproximação do cuidado do idoso ao efetuado às crianças (Mendes et al., 2018).

Assim, este estudo tem como objetivo compreender o planejamento da velhice nas famílias contemporâneas a partir da percepção de estudantes universitários. Optou-se por investigar a percepção dos estudantes universitários de uma Instituição de Ensino Superior (IES) privada, tendo em vista que são sujeitos em processo de formação e contínuo aprendizado, inseridos assim criticamente na sociedade. Possivelmente, por serem jovens adultos, estima-se que os mesmos têm ou terão algum familiar nessa fase da vida (velhice), além de trabalhar em algum momento com essa população, tendo em vista as perspectivas já mencionadas.

\section{Método}

A presente pesquisa configura-se em um estudo exploratório, de abordagem qualitativa, realizado através de grupo focal.

A seleção dos participantes para a pesquisa foi realizada de forma intencional, convidados através de redes sociais (Facebook, Instagram e WhatsApp) e por e-mail, sendo divididos em três grupos focais de um encontro. 0 convite foi estendido a estudantes de qualquer graduação, contudo, participaram somente estudantes da psicologia. Foram realizados grupos focais composto por um encontro, de aproximadamente duas horas. 13 universitários demonstraram interesse em participar dos grupos, sendo que somente 11 universitários participaram, sendo todos estudantes de psicologia. Contudo, pelo fato de um grupo focal ser composto somente por uma pessoa, desconfigurando a compreensão de grupo, os dados foram analisados a partir dos 10 universitários participantes dos dois grupos focais.

A coleta de dados foi realizada através de questionário sociodemográfico e de perguntas ao grupo focal. Os grupos ocorreram em uma sala de aula da Instituição de Ensino Superior (IES) privada. 0 questionário sociodemográfico 
teve por objetivo conhecer os participantes em termos de sexo, faixa etária, nível socioeconômico. As perguntas do grupo focal, construídas com base na literatura, levaram em consideração os seguintes temas: percepção sobre o envelhecimento, a qual buscou compreender como esses universitários interpretam esse processo; 0 conhecimento sobre o tema do planejamento da aposentadoria, verificando assim se existe al gum plano para o envelhecimento (Costa \& Bifano, 2017).

Os dados foram analisados através da análise temática, realizado em seis etapas (Braun \& Clarke, 2006). Através da identificação, análise e descrição de padrões ou temas, este método permitiu apresentar e organizar os dados de uma forma sintética, tendo o seu início com a transcrição dos dados, leitura e releitura dos dados e apontamento de ideias iniciais. A partir desse momento, foi possível gerar códigos iniciais, onde foram codificados os dados relacionados a cada código, sendo posteriormente agrupados em códigos iminentes, reunindo todos os dados relevantes para cada tema potencial. Contendo esses temas, foi realizada uma revisão dos mesmos, em que foi formado um "mapa" temático da análise. Com o "mapa" temático, foi realizada uma nova análise para aprimorar as especificidades de cada tema e, por último, foram selecionados exemplos a partir dos fragmentos dos grupos focais. Após a leitura do conteúdo das mensagens emergiram as duas categorias temáticas: A construção do envelhecimento contemporâneo na percepção de estudantes universitários e o planejamento da velhice é igual ao planejar a finitude?

Quanto aos procedimentos éticos, o projeto foi encaminhado ao Comitê de Ética em Pesquisa da Sociedade Educacional Ltda./FSG, conforme resolução n 510/16 do Conselho Nacional de Saúde (Brasil, 2016), tendo sido aprovado (protocolo (AAE18002619.9.0000.5668). Após a aprovação, os participantes foram recrutados através do diretório acadêmico do curso de psicologia e pelas mídias sociais. Os grupos focais foram realizados pela primeira autora, a partir da concordância do Termo de Consentimento Livre e Esclarecido. Os grupos focais foram gravados através de gravador de voz e posteriormente transcritos.

№ TCLE, constaram os objetivos da pesquisa, explicando que não era obrigatória a colaboração, bem como não haveria ganhos financeiros com a mesma e também não acarretaria custos ao participante. Também, a qualquer momento, o participante poderia desistir de participar do grupo sem qualquer prejuízo. Os participantes que demonstraram interesse receberam o retorno dos resultados através de uma oficina. Os questionários e seus dados foram armazenados com a pesquisadora responsável por um período mínimo de cinco anos e serão destruídos após este período.

\section{Resultados e Discussão}

Dos 10 participantes do estudo, oito eram do sexo feminino e dois do sexo masculino, com idades entre 23 e 35 anos ( $M=26,75$; $D P=3,74)$. Nenhum dos participantes possuía filhos e a maioria era solteiro, sendo apenas um universitário com união estável. Mais informações sobre as características sociodemográficas encontram-se na Tabela 1.

Tabela 1. Informações sociodemográficas

\begin{tabular}{||l|l|l|l|l|l|l||}
\hline Partic. & $\begin{array}{c}\text { Nível } \\
\text { socioeconômico da } \\
\text { família }\end{array}$ & $\begin{array}{c}\text { Familiar que } \\
\text { motivou a } \\
\text { participação } \\
\text { no grupo }\end{array}$ & $\begin{array}{c}\text { Idade do familiar } \\
\text { que motivou a } \\
\text { participação no } \\
\text { grupo }\end{array}$ & $\begin{array}{c}\text { Grau de instrução } \\
\text { dos pais }\end{array}$ & $\begin{array}{c}\text { Familiar(es) } \\
\text { idoso(s) }\end{array}$ & $\begin{array}{c}\text { Idade do(s) } \\
\text { familiar(es) } \\
\text { idoso(s) }\end{array}$ \\
\hline P 1. & Não soube informar & Mãe & 53 anos & Ensino médio incompleto & Avó materna & 72 anos \\
\hline P 2. & R\$ 7.000,00 & $\begin{array}{l}\text { Mãe } \\
\text { Pai }\end{array}$ & $\begin{array}{l}50 \text { anos } \\
47 \text { anos }\end{array}$ & $\begin{array}{l}\text { Ensino superior em } \\
\text { andamento } \\
\text { Ensino superior incompleto }\end{array}$ & $\begin{array}{l}\text { Avós } \\
\text { maternos }\end{array}$ & 70 anos \\
\hline P 3. & R\$ 15.000,00 & $\begin{array}{l}\text { Mãe } \\
\text { Pai }\end{array}$ & $\begin{array}{l}57 \text { anos } \\
60 \text { anos }\end{array}$ & $\begin{array}{l}\text { Ensino superior completo } \\
\text { Ensino médio completo }\end{array}$ & Avó & 81 anos \\
\hline P 4. & R\$ 2.000,00 & Mãe & 50 anos & Ensino fundam. completo & Avó & Avô \\
\hline P 5. & $\begin{array}{l}\text { R\$ 2.500,00 a } \\
\text { R\$ 3.000,00 }\end{array}$ & Mãe & 58 anos & Ensino médio completo & 76 anos \\
\hline P 6. & R\$ 5.000,00 & $\begin{array}{l}\text { Mãe } \\
\text { Pai }\end{array}$ & $\begin{array}{l}55 \text { anos } \\
53 \text { anos }\end{array}$ & $\begin{array}{l}\text { Ensino superior completo } \\
\text { Ensino fundam. incompleto }\end{array}$ & Avós & $\begin{array}{l}\text { Não soube } \\
\text { informar }\end{array}$ \\
\hline P7. & R\$ 4.000,00 & Mãe & $\begin{array}{l}53 \text { anos } \\
58 \text { anos }\end{array}$ & $\begin{array}{l}\text { Ensino médio incompleto } \\
\text { Ensino médio completo }\end{array}$ & Avó materna & $\begin{array}{l}\text { Não soube } \\
\text { informar }\end{array}$ \\
\hline P 8. & R\$ 2.000,00 & $\begin{array}{l}\text { Mãe } \\
\text { Pai }\end{array}$ & $\begin{array}{l}56 \text { anos } \\
65 \text { anos }\end{array}$ & $\begin{array}{l}\text { Ensino fundam. incompleto } \\
\text { Ensino fundam. incompleto }\end{array}$ & Avó & 83 anos \\
\hline P 9. & R\$ 2.500,00 & Mãe & 60 anos & Ensino fundam. incompleto & Madrinha & 89 anos \\
\hline
\end{tabular}




\section{A construção do envelhecimento contemporâneo na percepção de estudantes universitários}

Esta categoria representa as unidades de significado nas quais os universitários revelam as suas percepções e concepções de quem é esse idoso, o não saber nomear, a questão geracional e como o contexto influencia o processo. Os grupos consideram uma pessoa idosa a partir dos 60 anos, sendo ampliado para os 70 anos atualmente na percepção dos universitários. Esses números, segundo os universitários, podem mudar daqui alguns anos, pois depende de vários fatores e acreditam ser muito subjetivo.

"Eu também acredito que seja subjetivo, depende muito de como é a saúde física e mental da pessoa" (Part. 3).

A percepção de que não existe uma concepção única ou definitiva da velhice, mas sim concepções incertas, opostas e variadas, podendo considerar que, ao se tratar de idade, levamos em conta a idade cronológica, a psicológica e a social. Ou seja, a idade cronológica está ligada à biologia do sujeito, a psicológica é subjetiva e a social leva em conta a percepção da atuação para com os papéis esperados para sua idade (Papaléo Netto, 2017). Deste modo, em termos da biologia do sujeito, é possível discorrer acerca do corpo, que assume um importante papel no envelhecimento, uma vez que é nele que ocorrem as principais mudanças, seja na aparência ou na sua fisiologia (Esteves \& Fernandez, 2017).

"Cara quando tu perguntou, eu fiquei pensando que é tu estar mais vulnerável, mais suscetível a doenças, devido à idade enfim. Tá mais limitado[...] (Part. 8).

"Eu acho que a gente começa a perceber uma pessoa idosa, quando fisicamente ela começa a dar sinais disso. Como se fossem falhas do corpo, então ela começa ficar doente, começa a ir no médico, começa a aparecer os cabelos brancos, começa a ter [...] (Part. 2).

Esse corpo, desde as práticas ascéticas da antiguidade, é objeto de procedimentos e intervenções, que tinham como base o acesso à alma. Hoje, nas sociedades contemporâneas continuam os procedimentos e intervenções numa escala muito maior e invasiva, talvez com o objetivo de evitar, retardar ou tirar qualquer evidência do envelhecimento (Tavares \& Silva, 2019). Ao mesmo tempo, este corpo é o elo da relação entre o indivíduo e o grupo, que perpassa trocas simbólicas, normas e representações culturais de cada sociedade que se dá na construção deste corpo (Esteves \& Fernandez, 2017).

Essa cultura de exaltar o que éjovem, o que é belo e, com isso, a negação do velho foi percebida pelos universitários. Ao serem questionados sobre 0 que é ser idoso e ao pedir que definissem a velhice, os universitários ficaram em silêncio por alguns minutos.

"Tem definições que a gente nunca para pensar" (Part.1).
"Eu fico pensando aqui, essa dificuldade de falar uma palavra [...] Então a gente não se vê nesse lugar, que nem eu, eu até vejo os outros,mas eu não sei dizer outra palavra a não ser experiência. Onde é que eu tô nesse lugar? De futuramente idosa?"( Part. 3).

Segundo Ferrigno (2016), essa dificuldade está relacionada ao fato de se envelhecer em uma sociedade que valoriza a juventude e seus padrões de beleza. Assim, induz ao não pensar e, com isso, não conseguindo se imaginar nesse lugar, pode-se verificar uma possível recusa do envelhecimento. Logo, a cultura não estimula as pessoas a olharem para os fenômenos que fazem parte da existência e com os quais precisam de uma forma ou de outra nos deparar, como o envelhecimento e sua última etapa, a velhice. Por isso, aprendem a evitar e negar essas questões desde cedo (Tavares \& Silva, 2019). Desse modo, é possível identificar que a concepção de velhice tem sido relacionada à realidade que cada indivíduo vivencia, ocorrendo a partir de diferentes fatores, tais como, físico, biológico, psicológico, cultural (Faller,Teston \& Marcon, 2015).

"Então a pessoa é ativa, a gente não vê ela como idosa, quando ela começa a ficar menos ativa a gente vai vendo que ela ta idosa" (Part. 2).

"A questão física também é algo que me remete a ser idoso, a debilidade assim. Ea atividade eu acho que como o colega falou, ser menos ativo me remete a ser idoso" (Part. 6).

Resulta, desse modo, em um desejo de envelhecer bem e ter a garantia da qualidade de vida, ainda que seja necessário mostrar-se produtivo e ativo (Dourado, Oliveira \& Menezes, 2015). No entanto, percebe-se que esse ideal de velhice ativa é disseminado responsabilizando o sujeito, como se essa velhice fosse somente uma questão de escolhas, boas ou más. Questões como aspectos socioculturais, financeiros, de acesso a serviços básicos, os quais são aspectos coletivos que impactam diretamente nessa construção do ser idoso não podem ser esquecidos, uma vez que são considerados pilares para 0 envelhecimento ativo (Kreuz, 2018).

"[...] tirando a idade que obviamente ela chega pra todo 0 mundo né! Mas a idade tu nem tem como evitar, mas a escolha de vida tu tem como" (Part. 9).

"Faz lembrar a música do Chaves: "se você é jovem ainda, jovem ainda velhas não serás", essa música traz a juventude não morre a menos que tu deixa ela morrer" (Part. 7).

Por outro lado, os universitários revelaram perceber a influência do contexto e do ambiente sobre o papel e a imagem do ser idoso e de como viver essa fase e outras, ao decorrer das décadas. 
"Eu vejo até pela época que meus avós viveram, tipo meu avô paterno nasceu em 1912[...]. A mulher dele nasceu em 1916 [...] Então naquela época lá, o que aconteceu ela saiu de casa obrigada a se casar né. Teve que ter "dez mil filhos", ela queria estudar, ela queria ser artista e tal e não pôde [.... No tempo da minha avó materna, já foi um pouco diferente, porque ela nasceu em trinta e poucos [...] ela também saiu jovem de casa, para casar mas por escolha dela. Teve seus filhos, não teve tantos, teve 4 filhos [...] Foi uma mulher empreendedora, cuidava da casa ao mesmo tempo que trabalhava [...]mudou muito, vejo que mudou a forma de como o mundo move agora (Part. 3).

Desta forma, entende-se que a sociedade, em todas suas expressões dinâmicas, impacta e influencia os indivíduos coletiva e subjetivamente. É nesse intercâmbio constante entre subjetivo e o mundo social que a sociedade e, sobretudo o sujeito, se constitui (Morera, Padilha, \& Sapag, 2015). Com isso, representações sociais relacionadas ao idoso relativas à inutilidade, inatividade e de perda de autonomia tem influenciado no modo de se perceber a velhice (Brito et al., 2018; Faller,Teston \& Marcon, 2015). Neste sentido, o fato da velhice ser ainda associada à idade, parece influenciar na percepção de idosos sobre como é sentir-se velho (Faller,Teston \& Marcon, 2015).

Assim, conforme envelhecem, os papéis sociais esperados e impostos pela sociedade vão se modificando, principalmente no âmbito da família, em que se altera o lugar de cada integrante inserido nela. Essa modificação nas configurações familiares leva a reorganização dos papéis, tendo como resultado transformações sociais, como, por exemplo, a maior longevidade, o menor número de filhos e a saída da mulher para o mercado de trabalho (Scremin \& Bottoli, 2016). Corroborando com os autores, os participantes, em sua maioria, relataram que seus avós foram responsáveis pela sua educação, enquanto os seus pais trabalhavam.

"0 meu avô materno, até porque para os meus pais trabalharem eu ficava bastante com ele [...]Mas muita coisa que eu faço hoje, o jeito como eu me comporto é porque eu aprendi com ele" (Part.7).

"Ela (falecida mãe da mãe)cuidava de mim no caso[...]Então a minha mãe ia trabalhar e quem cuidava de mim era ela"(Part.4).

Deste modo, a presença dos avós parece ter influência nas crenças e na formação da personalidade dos estudantes universitários. Essa questão transgeracional é passada pelo sujeito detentor dessa herança que se divide entre o fim de si próprio e a continuação de ser uma conexão de intersubjetivação familiar, a qual está submetido. Desta forma, a questão transgeracional ou transmissão psíquica geracional remete à inserção do sujeito naquilo que é simbólico, ou seja, as palavras que ele aprende, estruturando a subjetividade e desenvolvendo psiquicamente tudo aquilo que é herdado (Louzeiro \& Lima, 2017).

\section{O planejamento da velhice é igual a planejar a finitude?}

Esta categoria representa as unidades de significado nas quais os participantes revelam um ideal de velhice e suas percepções quanto ao planejamento da velhice. Nestes temas, ao abordar o planejamento emergem associações a doenças, aposentadoria, situação financeira e finitude da vida.

"[...] na casa do meu avô, ele tá com 76 anos a minha mãe começou a pensar [...] bom vamos começar a pagar o seu plano funerário, pra quando chegar a hora tá tudo certinho! E entre nós (eu e ela) tudo certo, tudo bem termina o dele, começa a pagar 0 da minha mãe termina o dela, começa a pagar o meu. Era esse 0 raciocínio, mas quando a gente apresentou a ideia pra ele, mostrou a cartinha e tudo ele se invocou!" (Part. 5).

"Na minha família, por parte de mãe, eu percebo o cuidado com a saúde. Como todos tem em torno de 55, 56 anos ainda não chegaram aos 60, eles já começam a dizer: ah eu tô cuidando da minha saúde agora, física pra depois ter uma boa velhice" (Part.6).

Velhice e finitude são culturalmente associadas, sendo assuntos, muitas vezes, velados, evitados, negados, sendo considerados tabus. Essa associação deve-se em razão às perdas acumuladas ao longo dos anos e acentuadas nessa fase, aos anos que avançam e, a última instância, à frente que é a morte (Faller,Teston \& Marcon, 2016).

No que tange ao planejamento da velhice de seus familiares, a maioria dos participantes não tem um planejamento propriamente dito, nem que seja em termos de discussão sobre o envelhecer. Todos alegaram ser um assunto delicado e, muitas vezes, um tabu na família.

"[...]0 que a gente tem feito é cuidar mais da alimentação, mas nós nunca falamos pra velhice!" (Part. 8).

"Nenhum planejamento, de nada" (Part. 4).

0 fato de não haver um planejamento propriamente dito, ou melhor, ser um planejamento velado e/ou negado, pode ser compreendido como uma defesa, pois as atitudes e falas do outro para com esse tema, sinalizam para o sujeito que ele envelheceu ou está envelhecendo (Tavares \& Silva, 2019). Possivelmente, as representações sociais ligadas à velhice de ser uma fase de finitude influenciem neste não planejamento, uma vez que o idoso ainda pode continuar trabalhando e desenvolvendo novos projetos de vida (Faller,Teston \& Marcon, 2015). Desta forma, ficou evidente que talvez seja a primeira geração a viver por tanto tempo com as gerações anteriores e a primeira a começar a falar nessas temáticas. Sendo então uma realidade nova, os universitários só começaram a pensar e tiveram acesso a informação científica sobre 0 envelhecimento e a velhice através do curso de psicologia. 
"Eu fui ver o isso dentro da faculdade, fora disso muito pouco. Assim do que eu tive de contato com processo do envelhecimento que eu fui começando a entender, e ter alguns insights foi em função do curso de psicologia" (Part. 2).

0 curso de Psicologia possui, na maior parte das instituições, a disciplina de psicologia do envelhecimento, a qual tem por objetivo compreender a heterogeneidade do processo do envelhecimento humano e suas relações, proporcionando subsídios para reflexões de seus estudantes, perante o sujeito, suas relações e o processo que está vivenciando (Neri, 2017). Essa formação, voltada para uma concepção crítica sobre a velhice, compreendendo-a para além das mudanças físicas, torna-se imprescindível na formação de novos profissionais da saúde (Mendes et al., 2018).

Levando em consideração toda a evolução científica, bem como as transformações sociais, uma regra social ainda inserida é que o papel de cuidadora é da mulher, como do homem ser o provedor. Apesar das novas configurações familiares e os novos papéis, esse conceito ainda está latente em nossa sociedade.

"Isso é o que gente fala, bah mano a gente vai ter que cuidar do pai e da mãe! Já vai te preparando tu é o mais novo é tu que vai ficar em casa! Ai ele responde: mas tu é a mulher, é tu que fica!" (Part. 2).

Embora a mulher esteja cada vez mais no mercado de trabalho, ainda se espera que assuma as funções de cuidadora, em especial dos idosos. Vale ressaltar que essa função de cuidadora familiar foi construída historicamente e está fundamentada nos valores culturais e sociais da primeira metade do século passado, no qual as mulheres assumiam o papel domiciliar (Colussi, Pichler, \& Grochot, 2019).

Uma preocupação latente trazida pelos participantes com as novas configurações familiares refere-se ao fato de que, atualmente, não possuem mão de obra suficiente e/ou não gostariam de exercer tal papel de cuidador.

"É muito engraçado essa questão de associar: tu vai ter um filho e teu filho tem que te cuidar né!" (Part. 8).

"É eu ia dizer a mesma coisa, porque eu também sou filho único. Então eu também tenho esse pensamento, vou estabilizar financeiramente" (Part. 9).

Embora os participantes tenham associado que desejam filhos não para serem cuidados pelos mesmos, verifica-se que muitos filhos que cuidam de seus pais, esperam ser cuidados por seus filhos (Aires et al., 2019). Além disso, ficou evidente entre os universitários que a maioria tem sentimentos positivos de responsabilidade filial, ou seja, querem cuidar por dever e obrigação, aspecto que tem sido associado na realidade brasileira, embora sejam identificadas dificuldades vivenciadas por filhos cuidadores (Aires et al., 2019).

\section{Considerações finais}

A pesquisa permitiu compreender, através da percepção dos estudantes universitários, que o planejamento da velhice nas famílias contemporâneas ainda é um assunto em evolução. Cercado de tabus e medos, a velhice é vista pelos universitários como modificações biológicas e fisiológicas, com destaque para alterações na aparência externa, como a presença de cabelos brancos e rugas e 0 acometimento de doenças, provindas da idade, culminando na finitude.

Desta forma, vale considerar, desde cedo, abordar a morte/finitude como condição natural, inerente à vida humana. Para tanto, é necessário oferecer informação sobre ela e estimular discussões que levem à conscientização sobre sua naturalidade e inevitabilidade. Esse medo que cerca a finitude e associação quase simbiótica com a velhice, induz o sentimento de negação tanto dos avós e pais, bem como dos próprios estudantes universitários ao perceberem 0 envelhecimento.

Anula-se, assim, qualquer possibilidade de falar abertamente e planejar tal velhice. Deste modo, destaca-se a importância do papel da universidade para modificar a imagem do idoso no contexto atual, para todos os cursos e para a sociedade em geral. Percebe-se como limitação do presente trabalho, o interesse de somente um curso de graduação, o que limitou as percepções e contribuições acerca do tema.

Neste sentido, destaca-se a relevância deste estudo, pois, ao analisar a percepção dos universitários sobre o próprio envelhecimento e de seus pais, maiores informações são viabilizadas para a literatura científica, no intuito de identificar como estes vêem o envelhecimento e desmistificar os estereótipos inerentes a este processo. Também desperta e contribui para 0 conhecimento e aprimoramento das questões relacionadas ao indivíduo que está envelhecendo, buscando desenvolver pesquisas que compreendam a percepção do envelhecimento. Deste modo, fica o desejo de um diálogo mais aberto sobre a velhice em toda a sua complexidade, de forma ampla e com as suas singularidades, incluindo neste diálogo as diversas faixas etárias. Afinal, quem somos nós senão os velhos de amanhã?

\section{Referências}

Aires, M., Pizzol, F., Bierhals, C., Mocellin, D., Fuhrmann, A. C., Santos, N., Day, C., \& Paskulin, L. (2019). Responsabilidade filial no cuidado aos pais idosos: estudo misto. Acta Paulista de Enfermagem, 32(6), 691-699. doi:https:// dx.doi.org/10.1590/1982-0194201900095

Araújo, L., Castro, J., \& Santos, J. (2018). A família e sua relação com o idoso: um estudo de representações sociais. Psicologia em Pesquisa, 12(2), 14-23. doi: https://dx.doi.org/10.24879/2018001200200130

Brasil (2015). Aposentadoria: sancionada fórmula 85/95 para aposentadoria por tempo de contribuição. Recuperado em: http://www.previdencia. gov.br/2015/11/aposentadoria-sancionada-formula-8595-de-aposentadoria/.

Brito, A., Belloni, E., Castro, A., Camargo, B., \& Giacomozzi, A. (2018). Representações sociais do cuidado e da velhice no Brasil e ltália. Psicologia: Teoria ePesquisa, 34, 1-11. doi: https://dx.doi.org/10.1590/0102.3772e3455

Braun, V., \& Clarke, V. (2006). Using thematic analysis in psychology. Qualitative Research in Psychology, 3(2), 77-101.

Cachioni, M., \& Aguilar, L. E. (2008). Crenças em relação à velhice entre alunos da graduação, funcionários e coordenadores-professores envolvidos com as demandas da velhice em universidades brasileiras. Revista Kairós, 11(2), 95-119. 
Camarano, A. A., \& Kanso, S. (2017). Envelhecimento da população brasileira: uma contribuição demográfica. In de Freitas, E. V.\& Py, L. (Ed.). Tratado de geriatria e gerontologia. (pp. 209-233). Rio de Janeiro: Guanabara Koogan.

Colussi, E. L., Pichler, N. A., \& Grochot, L. (2019). Percepções de idosos e familiares sobre envelhecimento. Revista Brasileira de Geriatria e Gerontologia,22(1), 1-8. doi:10.1590/1981-22562019022.180157.

Costa, E.0., \& Bifano, A.C.S. (2017). A análise institucional como instrumento para compreender a reinstitucionalização de idosos na família contemporânea: um estudo de caso. Sociedade em Debate, 23(2), 305-330.

Dourado, M. B., Oliveira, A. L. B. de \& Menezes, T. M. de 0. (2015). Percepção dos graduandos de enfermagem sobre o seu envelhecimento. Revista Brasileira de Enfermagem, 68 (2), 278-283. doi: 10.1590/0034-7167.2015680213i.

Esteves, D. B., \& Fernandez, J. C. A. (2017). Velhice, corpo e saúde. Revista Kairós-Gerontologia, 20(4), 383-401. doi: 10.23925/2176-901X. 2017v20i4p383-401.

Faller, L., Teston, E., \& Marcon, S. (2015). A velhice na percepção de idosos de diferentes nacionalidades. Texto \& Contexto-Enfermagem, 24(1), 128-137. doi:https://dx.doi.org/10.1590/0104-07072015002170013

Ferrigno, J. C. (2016). A Psicologia das derradeiras fases da vida. Mais 60Estudos sobre Envelhecimento, 27(66), 68-83.

Louzeiro, C. F. A. \& Lima, A. B. R. (2017). Família e envelhecimento: um estudo sobre as relações entre avós e netos. Revista Ceuma Perspectivas, 30(1), 132-149.doi:https://doi.org/10.24863/rccp.v30i2.108

Kreuz, G. (2018). EnvelheSER: Processo individual e coletivo. Revista portal de divulgação, 55, 49-53. Disponível em: https://revistalongeviver.com.br/ index.php/revistaportal/article/viewFile/697/767

Mendes, J., Massi, G., Willig, M., Ziesemer, N., Silva, A., \& Carvalho, T. (2018). Representações sociais da velhice e do cuidado enunciadas por acadêmicos de fonoaudiologia e de enfermagem. Distúrbios da Comunicação, 30(2), 402-410. doi:https://doi.org/10.23925/2176-2724.2018v30i2p-402-410

Miranda, G. M. D., Mendes, A. Da C. G., \& da Silva, A. L. A. (2016). 0 envelhecimento populacional brasileiro: desafios e consequências sociais atuais e futuras. Revista Brasileira de Geriatria e Gerontologia, 19(3), 507-519. doi: 10.1590/1809-98232016019.150140.

Morera, J. A. C., Padilha, M. I., da Silva, D. G. V., \& Sapag, J. (2015). Aspectos teóricos e metodológicos das representações sociais. Texto \& Contexto Enfermagem, 24(4), 1157-1165. doi: 10.1590/0104-0707201500003440014.

Neri, A. L. (2017). Teorias psicológicas do envelhecimento/ Percurso histórico e teorias atuais. In de Freitas, E. V.\& Py, L. (Ed.). Tratado de geriatria e gerontologia. (pp. 152-179). Rio de Janeiro: Guanabara Koogan.

Papaléo Netto, M. (2017). Estudo da velhice/ Histórico, definição do campo e termos básicos. In de Freitas, E. V.\& Py, L. (Ed.). Tratado de geriatria e gerontologia. (pp. 103-125). Rio de Janeiro: Guanabara Koogan

Reis, C., \& Monteiro, C. (2016). Velhice na contemporaneidade: uma análise psicossocial. Revista Uningá, 50, 71-76.

Scremin, A. L. X. \& Bottoli, C. (2016). Avós e netos: o exercício de uma parentalidade. Barbarói, 48(1), 234-252.doi: http://dx.doi.org/10.17058/ barbaroi.v0i48.5486

Tavares, L. N., \& Silva, L. C. da, (2019). A velhice e a exterioridade: 0 olhar do outro na velhice, uma compreensão existencial. Revista Kairós-Gerontologia, 22(1), 405-419. doi: 10.23925/2176-901X.2019v22i1p405-419. 